\title{
Postoperative improvement in acoustic rhinometry measurements after septoplasty correlates with long-term satisfaction*
}

\author{
Navid M. Toyserkani, Thomas Frisch, Christian von Buchwald \\ Department of Otolaryngology, Head and Neck Surgery, Rigshospitalet and Faculty of Health Sciences, \\ University of Copenhagen, Denmark
}

Rhinology 51: 171-175, 2013

DOI:10.4193/Rhino12.163

*Received for publication:

October 2, 2012

Accepted: February 5, 2013

\section{Summary}

Background: Not much is known about long-term satisfaction of septoplasty. Our goal was to compare pre- and postoperative acoustic rhinometry measurements with satisfaction 11 years after surgery.

Methodology: Acoustic rhinometry measurements were performed preoperatively and 3 months postoperatively. Satisfaction was evaluated with semi-structured interviews by telephone 11 years after surgery. Symptoms were evaluated using the NOSE score.

Results: In total, 222 patients were interviewed and eligible to enter the study. Of these, 213 had preoperative acoustic rhinometry and 159 had postoperative acoustic rhinometry. In total, 157 patients had a complete data set. Mean follow-up time was 11.3 years. Patients satisfied with surgery had a bigger improvement in total minimum cross-sectional area before decongestion and total nasal cavity volume after decongestion. NOSE scores were not correlated with acoustic rhinometry measurements.

Conclusion: Acoustic rhinometry could be a valuable tool for evaluating the results of septoplasty. Satisfaction at 11 years followup was associated with 3 months postoperative acoustic rhinometry improvements. Acoustic rhinometry did not show preoperative patient selection potential.

Key words: nasal obstruction, nasal septum, treatment outcome, patient satisfaction, acoustic rhinometry

\section{Introduction}

Nasal obstruction is a common problem managed in otorhinolaryngology. Difficulty with nasal breathing can have many causes but often a deviated nasal septum is the cause. This can vary in severity and the prevalence of septal deviation has been reported to be up to $80 \%{ }^{(1)}$. As such, the deviated septum is not always the problem but if believed so the definitive treatment for this is surgical correction, and septoplasty is one of the most commonly performed surgical procedures by otolaryngologists $^{(2)}$.
Nasal obstruction symptoms are subjective and do not always coincide with nasal cavity findings. Thus, objective measures have been proposed such as active anterior rhinomanometry, acoustic rhinometry and nasal peak flow. These methods, however, have produced mixed results regarding the correlation with subjective symptoms and there is no agreement on a measurement tool ${ }^{(3-6)}$.

Acoustic rhinometry (AR) measures the geometry of the nose by means of acoustic reflections. Studies comparing acoustic 
rhinometry with computed tomography or magnetic resonance imaging have shown a good correlation in the anterior portion of the nasal cavity but not the posterior part ${ }^{(7-12)}$. By measuring the nasal cavity before and after decongestant application, the mucosal part of nasal obstruction can be evaluated. Its principle and limitations have been described in detail elsewhere ${ }^{(13)}$. Not all patients report improved nasal breathing after septoplasty and long term subjective satisfaction has been shown to be as low as $56-69 \%{ }^{(14,15)}$. It would be optimal if a method for selecting patients for septoplasty was available to physicians as to avoid operating on patients with no achievable gain.

The aim of this study was to investigate if pre- and postoperative acoustic rhinometry was correlated to long-term satisfaction after septoplasty with or without additional nasal surgery in a university hospital setting.

\section{Materials and methods}

\section{Setting}

This study was performed in a university hospital setting (secondary and tertiary referral center).

\section{Inclusion criteria}

Patients who underwent septoplasty in the time period of January 1999 and December 2000 were all included in the study if the indication was nasal obstruction and/or snoring. This included patients undergoing septoplasty alone or in combination with other nasal surgery to represent a typical population representing with nasal obstruction.

\section{Exclusion criteria}

Patients whose indication for septoplasty was not nasal obstruction or snoring were excluded. Patients with sinus surgery either before or after septoplasty and patients with acute nasal trauma were excluded from the study. Patients who in the follow-up period had broken their nose were also excluded.

\section{Study design}

The study was conducted as a follow-up questionnaire survey, related to initial prospective examinations.

\section{Outcome measures}

In spring 2011, all patients were sent a postal questionnaire and asked how satisfied they were with the overall result on a 5 point likert scale where 0 was very unsatisfied and 4 was very satisfied with the overall result of surgery. This was later reduced to either "Not satisfied" or "Satisfied" where the options satisfied and very satisfied comprised the "Satisfied" group. The patients were asked about their symptoms before surgery and today using the NOSE score ${ }^{(16)}$. AR was performed before operation in the period 3 months before surgery to same day. Postoperative
AR was performed 3 months after surgery. The following measures were made before and 30 minutes after decongestion based on the mean value of three measurements (Figure 1):

Minimal cross-sectional area 1

(MCA1): $0-2.20 \mathrm{~cm}$

Minimal cross-sectional area 2

(MCA2): $2.21-5.40 \mathrm{~cm}$

Minimal cross-sectional area 3

(MCA3) $0-5.40 \mathrm{~cm}$

Nasal cavity volume 1

(VOL1): $0-2.20 \mathrm{~cm}$

Nasal cavity volume 2

(VOL2): $2.21-5.40 \mathrm{~cm}$

Nasal cavity volume 3

(VOL3): $0-5.40 \mathrm{~cm}$

Nasal congestion index $(\mathrm{NCl})^{(17)}$ was calculated for MCA3 and VOL3 based on the following formulas:

NCI-MCA3: (MCA3decongested - MCA3before decongestion) / MCA3before decongestion

NCI-VOL3: (VOL3decongested - VOL3before decongestion) / VOL3before decongestion

\section{Statistical analysis}

IBM SPSS Statistics 20 was used for all statistical analysis. Independent samples t-test was used to compare data between satisfied and not satisfied patients and paired samples t-test was used for paired data. Spearman's rank correlation coefficient was used to test for correlation between NOSE scores and acoustic rhinometry measurements. A two-tailed $p$ value less than 0.05 was considered statistically significant.

\section{Results}

A total of 506 patients underwent nasal septal surgery alone or in combination with other nasal procedures over a 24-month period between January 1999 and December 2000. In total, 222 were interviewed and eligible.

Of these 222, 213 patients had preoperative acoustic rhinometry and 159 had postoperative acoustic rhinometry. In total, 157 had both preoperative and postoperative acoustic rhinometry.

No difference in patient satisfaction or acoustic rhinometry data was observed between patients with both measurements compared with patients who only had preoperative acoustic rhinometry. Statistical analysis was based on patients with a complete dataset. No significant difference in acoustic rhinometry parameters was observed between patients who completed the questionnaire and patients not included in the study. Basic acoustic rhinometry measurements were all significantly improved postoperatively (Table 1). Mean follow-up time was 11.3 years (range 10.2 - 12.2 years).

At follow-up, $55.9 \%$ of patients were either pleased or very pleased with their result (the satisfied group), while $27 \%$ were 


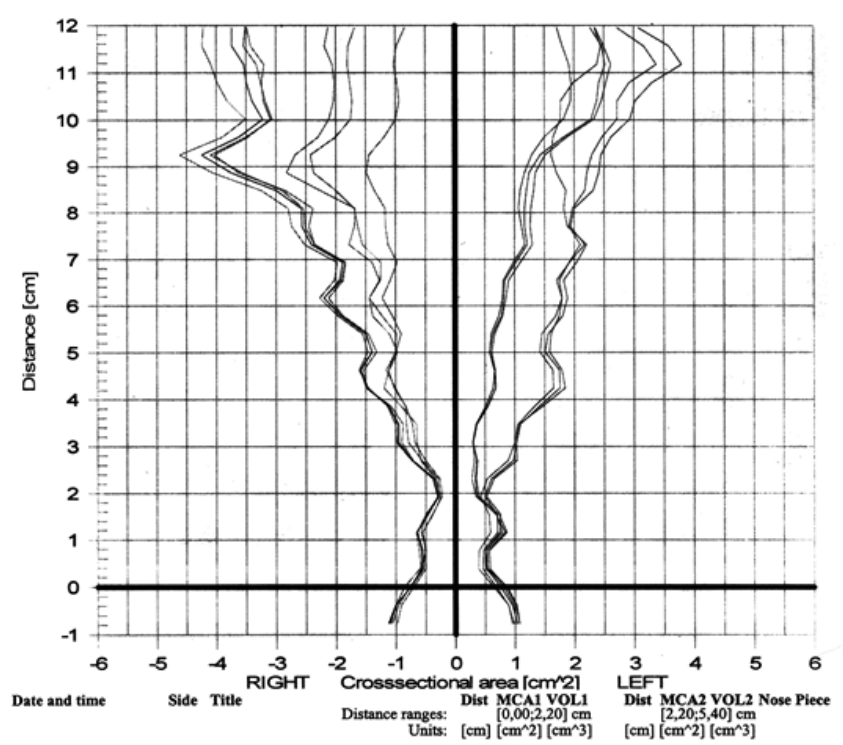

Figure 1. Standard acoustic rhinometry diagram before and after decongestion.
Table 1. Acoustic rhinometry measurements pre- and postoperatively before and after decongestion were all improved. Values are mean \pm SD.

\begin{tabular}{|lcccc|} 
& \multicolumn{2}{c}{ Before decongestion } & \multicolumn{2}{c|}{ After decongestion } \\
& $\begin{array}{c}\text { Pre } \\
\text { operative }\end{array}$ & $\begin{array}{c}\text { Post } \\
\text { operative }\end{array}$ & $\begin{array}{c}\text { Pre } \\
\text { operative }\end{array}$ & $\begin{array}{c}\text { Post } \\
\text { operative }\end{array}$ \\
\hline MCA1+ & $0.85 \pm 0.23$ & $0.95 \pm 0.22^{*}$ & $0.92 \pm 0.23$ & $1.03 \pm 0.22^{*}$ \\
\hline MCA2 & $0.86 \pm 0.24$ & $0.98 \pm 0.27^{*}$ & $1.12 \pm 0.27$ & $1.19 \pm 0.34 \#$ \\
\hline MCA3 & $0.74 \pm 0.19$ & $0.87 \pm 0.21^{*}$ & $0.87 \pm 0.20$ & $0.99 \pm 0.21^{*}$ \\
\hline VOL1- & $3.46 \pm 0.62$ & $3.55 \pm 0.62 \#$ & $3.48 \pm 0.61$ & $3.57 \pm 0.60 \#$ \\
\hline VOL2 & $6.03 \pm 1.49$ & $8.00 \pm 1.77^{*}$ & $9.68 \pm 1.96$ & $11.28 \pm 2.03^{*}$ \\
\hline VOL3 & $9.48 \pm 1.73$ & $11.56 \pm 1.98^{*}$ & $13.16 \pm 2.21$ & $14.85 \pm 2.26^{*}$
\end{tabular}

" postoperative change was significant $(p<0.01)$

" postoperative change was significant $(p<0.001)$

+ MCA: Minimum cross-sectional area. 1: 0-2.20cm, 2: $2.21-5.40 \mathrm{~cm}$, 3: $0-5.40 \mathrm{~cm}$

-VOL: Nasal cavity volume. $1: 0-2.20 \mathrm{~cm}, 2: 2.21-5.40 \mathrm{~cm}, 3: 0-5.40 \mathrm{~cm}$ MCA unit is $\mathrm{cm}^{2}$ and VOL unit is $\mathrm{cm}^{3}$. unsatisfied or very unsatisfied and $17.1 \%$ were in between (not satisfied group) ${ }^{(15)}$. No difference in basic preoperative acoustic rhinometry measures was observed between satisfied and not satisfied patients. Patients satisfied with the overall result of surgery had a bigger improvement in total minimum cross-sectional area before decongestion $\left(0.17 \pm 0.20\right.$ vs $0.10 \pm 0.19 \mathrm{~cm}^{2}$, $\mathrm{p}<0.05)$ and total volume of the nasal cavity after decongestion $\left(2.08 \pm 2.74\right.$ vs $\left.1.25 \pm 2.40 \mathrm{~cm}^{3}, \mathrm{p}<0.05\right)$. No significant difference was seen in split area measurements (Table 2).

Nasal congestion index for MCA3 before surgery was significantly higher amongst satisfied patients. A significant decrease in $\mathrm{NCl}-\mathrm{MCA} 3$ was seen postoperatively amongst satisfied patients. $\mathrm{NCl}$ for total nasal cavity volume was not correlated with satis- faction (Table 3).

A meaningful cut-off value for acoustic rhinometry measures could not be found using Retriever Operating Characteristics Curve.

Severity of nasal obstruction defined by review of case notes was not correlated with either satisfaction or any acoustic rhinometry variable. NOSE scores before surgery and today were not correlated with acoustic rhinometry measurements. Smoking status before surgery was associated with less decongestive ability of the nasal mucosa determined by NCI-VOL3 both before and after surgery $(p<0.01)$. Smoking status at follow-up was correlated with a lower satisfaction rate, though this was not seen in any acoustic rhinometry parameter ${ }^{(15)}$.

Table 2. Acoustic rhinometry improvements were greater for satisfied patients. Values are mean \pm SD.

\begin{tabular}{|c|c|c|c|c|c|}
\hline & & \multicolumn{2}{|c|}{ Before decongestion } & \multicolumn{2}{|c|}{ After decongestion } \\
\hline & & Preoperative & Postoperative & Preoperative & Postoperative \\
\hline \multirow[t]{2}{*}{$\mathrm{MCA}^{+}$} & Satisfied & $0.72 \pm 0.20$ & $0.89 \pm 0.21^{*}$ & $0.86 \pm 0.21$ & $0.99 \pm 0.22$ \\
\hline & Not satisfied & $0.76 \pm 0.18$ & $0.86 \pm 0.20$ & $0.87 \pm 0.19$ & $0.98 \pm 0.20$ \\
\hline \multirow[t]{2}{*}{ - VOL3 } & Satisfied & $9.57 \pm 1.75$ & $11.86 \pm 2.04$ & $13.00 \pm 2.24$ & $15.08 \pm 2.28^{*}$ \\
\hline & Not satisfied & $9.38 \pm 1.72$ & $11.14 \pm 1.93$ & $13.35 \pm 2.19$ & $14.62 \pm 2.30$ \\
\hline
\end{tabular}

\footnotetext{
* Postoperative improvement was significantly higher among satisfied patients $(p<0.05)$

+ MCA3: Total minimum cross-sectional area between $0-5.40 \mathrm{~cm}$

- VOL3: Total nasal cavity volume between $0-5.40 \mathrm{~cm}$

MCA unit is $\mathrm{cm}^{2}$ and VOL unit is $\mathrm{cm}^{3}$.
} 
Table 3. Nasal congestion index for total minimal cross-sectional area decrease among satisfied patients. Values are mean $\pm S D$.

\begin{tabular}{cccc} 
& & $\begin{array}{c}\text { Preoperative } \\
\text { value }\end{array}$ & $\begin{array}{c}\text { Postoperative } \\
\text { decrease }\end{array}$ \\
\hline+ NCI-MCA3 & Satisfied & $0.23 \pm 0.22$ & $0.09 \pm 0.26^{*}$ \\
& Not satisfied & $0.16 \pm 0.16$ & $0.00 \pm 0.18$
\end{tabular}

* Postoperative change was significant between satisfied and not satisfied patients $(p<0.05)$

+ NCl-MCA3: Nasal congestion index for total minimal cross-sectional area between $0-5.40 \mathrm{~cm}$.

\section{Discussion}

Selection criteria for septoplasty are far from evidence based and today patients are often booked for surgery without any objective measurements of the nose. Dinis et al. argued that inappropriate indication for septal surgery was one of the major reasons for patient dissatisfaction ${ }^{(18)}$. Objective nasal measurements could potentially aid in selecting patients for surgery. However objective nasal measurements and subjective symptoms are not always correlated ${ }^{(3-5)}$. It could be argued though that they evaluate the patient from two different angles and as such do not necessarily need to be correlated. When offering a patient septoplasty, the surgeon believes that by redistributing the nasal cavity dimensions subjective symptoms of nasal obstruction will decrease. If the patient is not improved postoperatively, acoustic rhinometry can provide an objective measure for what changes have taken place in the nasal cavity due to surgery. Therefore, acoustic rhinometry can potentially allow surgeons to objectively evaluate the result of septoplasty since relying exclusively on subjective symptoms in today's evidence based medicine is hardly satisfactory.

In our study with only $56 \%$ satisfied patients, a significant improvement in all acoustic rhinometry parameters was seen postoperatively. This suggests that the operative technique was not the main reason for such a low satisfaction rate. Satisfied patients had a bigger improvement in MCA3 before decongestion and total nasal cavity volume after decongestion. This suggests that the increase in nasal cavity dimensions following surgery is at least to some extent long-lasting even 11 years after surgery. Pirilla et al. showed that one year satisfaction after septoplasty was correlated with preoperative acoustic rhinometry findings ${ }^{(6)}$. Besides a higher $\mathrm{NCl}-\mathrm{MCA} 3$, we did not find any preoperative difference between satisfied and not satisfied patients. A meaningful cut-off value for any acoustic rhinometry variable for predicting satisfaction was not found in our study.

Higher $\mathrm{NCl}-\mathrm{MCA} 3$ preoperative was seen among satisfied patients and a reduction in $\mathrm{NCl}-\mathrm{MCA} 3$ postoperatively was associated with satisfaction as well. Postoperative acoustic rhinometry was performed 3 months after surgery and as such the decongestive ability of the mucosa could still be affected by scarring and whether this change in $\mathrm{NCl}$ is permanent or transient is impossible to tell without new measurements. Given the fact that satisfaction 11 years postoperatively is correlated with this variable, one could assume that this decrease has permanent benefits.

Subjective symptoms were estimated using NOSE scores before surgery and at follow-up and they were not correlated with acoustic rhinometry measurements. As previously mentioned, this is a normal finding and since our patients had to estimate their symptoms before surgery retrospectively, uncertainty is attached to this part of the study.

Although our study aimed to evaluate the possible role of acoustic rhinometry in the evaluation of septoplasty our results should be evaluated with some caution. First, only $71 \%$ of patients included in the study had both pre- and postoperative acoustic rhinometry. The main reason for this was that patients did not show up for their routine 3 month postoperative checkup. Another weakness of this study is the lack of a new acoustic rhinometry test at follow-up 11 years after surgery. This has been omitted because a very low patient count was expected for such an arrangement.

\section{Conclusion}

In conclusion, acoustic rhinometry could be a valuable tool for evaluating the results of septoplasty especially in cases where subjective and objective findings diverge. Acoustic rhinometry did not show preoperative patient selection potential.

Satisfaction at 11 years follow-up was associated with 3 months postoperative acoustic rhinometry improvements.

\section{Acknowledgement}

There was no funding for this project.

\section{Authorship contribution}

NMT has gathered all data from case files, interviewed the patients by telephone, made the statistical analysis and wrote the article. TF and CB have supervised the project and contributed to writing the article.

\section{Conflict of interest}

There are no conflicts of interest. 


\section{References}

1. Gray LP. Deviated nasal septum. Incidence and etiology. Ann Otol Rhinol Laryngo Suppl. 1978; 87, Suppl 50: 3-20.

2. Mlynski G. Surgery of the nasal septum Facial Plast Surg. 2006; 22: 223-229.

3. Andre RF, Vuyk HD, Ahmed A, Graamans K, Nolst Trenite GJ. Correlation between subjective and objective evaluation of the nasa airway. A systematic review of the highest level of evidence. Clin Otolaryngol. 2009; 34: 518-525.

4. Kahveci OK, Miman MC, Yucel A, Yucedag F, Okur E, Altuntas A. The efficiency of Nose Obstruction Symptom Evaluation (NOSE) scale on patients with nasal septal deviation. Auris Nasus Larynx. 2012; 39: 275-279.

5. Larsson C, Millqvist E, Bende M. Relationship between subjective nasal stuffiness and nasal patency measured by acoustic rhinometry. Am J Rhinol. 2001; 15: 403-405.

6. Pirila T, Tikanto J. Acoustic rhinometry and rhinomanometry in the preoperative screening of septal surgery patients. Am J Rhinol Allergy. 2009; 23: 605-609.

7. Corey JP, Gungor A, Nelson R, Fredberg J, La $\checkmark$. A comparison of the nasal cross-sectional areas and volumes obtained with acoustic rhinometry and magnetic resonance imaging. Otolaryngol Head Neck Surg. 1997; 117 349-354.
8. Dastidar P, Numminen J, Heinonen T, Ryymin P, Rautiainen M, Laasonen E. Nasal airway volumetric measurement using segmented HRCT images and acoustic rhinometry. Am J Rhinol. 1999; 13: 97-103.

9. Gilain L, Coste A, Ricolfi F, et al. Nasal cavity geometry measured by acoustic rhinometry and computed tomography. Arch Otolaryngol Head Neck Surg. 1997; 123 401-405.

10. Min YG, Jang YJ. Measurements of crosssectional area of the nasal cavity by acoustic rhinometry and CT scanning. Laryngoscope. 1995; 105: 757-759.

11. Munoz-Cano R, Salvador R, Valero A, et al. Accuracy of acoustic rhinometry versus computed tomography in the evaluation of nasal cavity in patients with nasal polyposis. Rhinology. 2010; 48: 224-227.

12. Numminen J, Dastidar $P$, Heinonen $T$, Karhuketo T, Rautiainen M. Reliability of acoustic rhinometry. Respir Med. 2003; 97 : 421-427.

13. Hilberg O. Objective measurement of nasal airway dimensions using acoustic rhinometry: methodological and clinical aspects. Allergy. 2002; 57, Suppl 70: 5-39.

14. Jessen M, Ivarsson A, Malm L. Nasal airway resistance and symptoms after functional septoplasty: comparison of findings at 9 months and 9 years. Clin Otolaryngol Allied
Sci. 1989; 14: 231-234.

15. Toyserkani NM, Frisch T. Are too many septal deviations operated on? A retrospective patient's satisfaction questionnaire with 11 years follow-up. Rhinology. 2012; 50: 185-190.

16. Stewart MG, Witsell DL, Smith TL, Weaver EM, Yueh B, Hannley MT. Development and validation of the Nasal Obstruction Symptom Evaluation (NOSE) scale. Otolaryngol Head Neck Surg. 2004; 130: 157-163.

17. Kjaergaard T, Cvancarova M, Steinsvag SK. Nasal congestion index: A measure for nasal obstruction. Laryngoscope. 2009; 119: 1628-1632.

18. Dinis PB, Haider H. Septoplasty: long-term evaluation of results. Am J Otolaryngol. 2002; 23) :85-90.

Navid M. Toyserkani

Slotsfogedvej $72 . t v$

2400 København NV

Denmark

Tel: $+45-50383833$

E-mail: DRG777@ALUMNI.KU.DK 